\title{
NUMERICAL MODELING OF GASEOUS PARTIALLY PREMIXED LOW-SWIRL LIFTED FLAME AT ELEVATED PRESSURE
}

\author{
Leonardo Langone ${ }^{1}$, Julia Sedlmaier ${ }^{2}$, Pier Carlo Nassini ${ }^{1}$, Lorenzo Mazzei ${ }^{1}$, \\ Stefan Harth ${ }^{2}$, Antonio Andreini ${ }^{1 *}$ \\ ${ }^{1}$ Department of Industrial Engineering \\ University of Florence \\ via S.Marta, 3 Florence, 50139, Italy \\ 2 Engler-Bunte-Institute \\ Division of Combustion Technology \\ Karlsruhe Institute of Technology \\ Karlsruhe, Germany
}

\begin{abstract}
Lifted flames have been investigated in the past years for their benefits in terms of NOx emissions reduction for gas turbine applications. In a lifted flame, the flame front stabilized on a position that is significantly detached from the nozzle exit, improving the premixing process before the reaction zone. The distance between the flame front and the nozzle exit is called liftoff height and it represents the main parameter that characterize this type of flame. In the present work, a partially premixed lifted flame employing air-methane mixture is investigated through numerical simulation. Indeed, even if lifted jet flames have been widely studied in the literature, there are only a few examples of lifted partially premixed flames. Nevertheless, this kind of flames assumes an important role considering the current gas turbine applications, since their benefits in terms of stability and low pollutant emissions. This study has been performed with LES calculations using a commercial software suite and the numerical results are compared with experimental data coming from a dedicated campaign held at Karlsruher Institute für Technologie (KIT) on a novel low-swirl injector nozzle. Quenching effects due
\end{abstract}

to strain, curvature and heat loss have been introduced into the combustion model thanks to a correction of the source term in the progress variable equation within the FGM model. The comparison between numerical results and experimental data have been performed in terms of lift-off height and $\mathrm{OH}^{*}$ chemiluminescence maps, showing the capability to properly predict the overall flow and to catch flame lift-off even if with an underpredicted height. This points out promising capability of the numerical model in the representation of lifted flames, allowing further investigations of the flame structure otherwise not available from experimental techniques.

\section{NOMENCLATURE \\ Symbols \\ A Flame surface area \\ a Strain rate \\ c Normalized progress variable \\ $C_{S} \quad$ Smagorinsky constant}


n Flame front normal unity vector

$S_{c} \quad$ Consumption speed

$S_{c}^{0} \quad$ Unstretched laminar consumption speed

$T$ Temperature

$Y_{i} \quad$ Mass fraction of species i

$Y_{c} \quad$ Non-normalized progress variable

$z \quad$ Mixture fraction

$\delta_{l}^{0} \quad$ Laminar flame front thickness

$\Delta \quad$ LES filter length

$\lambda \quad$ Fuel to air equivalence ratio

$\Pi_{k} \quad$ Efficiency function

$\kappa \quad$ Flame stretch

$\Gamma_{\kappa, \psi} \quad$ Correction factor

$v_{t} \quad$ Eddy viscosity

$\sigma_{c} \quad$ Flame front curvature

$\tau \quad$ Sub-grid time scale

$\psi \quad$ Heat loss correction parameter

$\dot{\omega}_{c} \quad$ Progress variable source term

$\dot{\omega}_{F} \quad$ Fuel net production rate

\section{Acronyms}

$\begin{array}{ll}\text { CFD } & \text { Computational Fluid Dynamics } \\ F G M & \text { Flamelet Generated Manifold } \\ G T & \text { Gas Turbine } \\ \text { LES } & \text { Large Eddy Simulation } \\ \text { LOH } & \text { Lift-Off Height } \\ P D F & \text { Probability Density Function } \\ P L I F & \text { Planar Laser Induced Fluorescence } \\ P V & \text { Progress Variable } \\ R A N S & \text { Reynolds-Averaged Navier-Stokes } \\ R Z & \text { Recirculation Zone }\end{array}$

\section{INTRODUCTION}

Low pollutant emissions, operational safety and flame stability are nowadays mandatory features for modern gas turbines. For these reasons, in recent years, many research efforts have been focused on the physics phenomena which occur inside the combustion chamber. The use of lean premixed mixture, mostly for gaseous fuels, permits in principle to precisely control fuelair mixing avoiding high local flame temperature responsible of NOx formation, but may quickly lead to flame instabilities limiting engine operability by reducing Lean Blow Out margin and generating thermoacoustics fluctuations. To extend the practical adoption of lean premixed concept, many solutions based on partially premixed flames (stratified flames or piloted flames) have been proposed, since their twofold advantage of improved stability and potential in emission reduction [1]. Similar solutions have been recently developed also in the aero-engine combustors operated with lean burn spray flames [2]. In most common cases flame stabilization is achieved by promoting local low mixture velocity supported by large hot gases recirculation produced by the breakdown of high swirling jets [3] or with the adoption of diffusive pilot flames used to anchor high velocity/high turbulence ultra-lean premixed jets with high flashback resistance [4].

A possible alternative solution might be represented by lifted flames, namely flames remarkably detached from the nozzle exit at a distance called Lift-Off Height (LOH). They are generated by separated inlet streams of fuel and air which undergo to premixing directly inside the chamber, with the aim of reaching the flame edge with an adequate lean composition to allow low NOx combustion. Since the premixing process occurs directly inside the combustion chamber, no premixing devices are required, limiting the risk of flashback. Furthermore, this type of flame increases the nozzle life, avoiding coking phenomena at the stabilization rim of the injector. Although this type of flame has been widely investigated both experimentally and numerically for years, the majority of published works deal with nonpremixed jet flames, often operated with air co-flow. Lift-off definition appeared for the first time in [5]: according to Wohl et al., it can be seen as a result of the exceed of a critical velocity gradient value at the stabilization rim for a diffusive flame. From this point, many studies have been conducted on different configurations very often with the aim of describing and explain the stabilization process bringing to flame lift-off. A detailed description in this direction is given in the literature review done by Lyons [6], where the theories on the stabilization mechanisms previously proposed are discussed considering experiments contributions. A summary of the described theories is here reported: Premixing level: one of the most important theories about lifted flame stabilization states that it occurs at the position where the mean flow velocity at the contour of the mean stoichiometric mixture equals the turbulent burning velocity of a stoichiometric premixed flame (Vanquickenborne and Van Tiggelen [7]). The more recent theory sees the flame base as partially premixed and propagating upstream to counter the local flow-field while modifying it through the heat-release $[8,9]$;

Turbulence effects: turbulence has surely a great impact on the combustion processes. Turbulence intensity enhances the burning velocity and this value should be related to the flame leadingedge position. From another point of view, the large scale should be the drivers of flame stabilization, since the flame leading-edge might be attached to large eddies, being allowed to migrate to the upstream neighboring structures and hence stabilizing the reaction zone [10];

Local extinction: flame stabilization is controlled by quenching phenomena that occurs due to the flow field characteristics and heat losses. This theory has been proposed by Peters [11], which states that the stability position is placed where the relevant scalar dissipation rate falls below a critical value;

By looking individually at each of those theories, none of them is capable of a complete description of the stabilization mechanism for turbulent lifted flames and likely this position might be related to a combination of all the three categories, as 
largely demonstrated by Lyons. Summarizing, the above mentioned reviews collect very interesting considerations about stabilization mechanisms for lifted flames but they are mainly related to unconfined jet flames, which actually is a configuration not really representative of the flames employed in a modern GT combustor.

The most interesting practical implementations of lean burn lifted flames for GT applications are those based on low-swirl partially premixed mixtures studied by [12-14] and more recently by the Engler-Bunte Institut (EBI) at the Karlsruher Institut für Technologie (KIT) $[15,16]$, where the extension to spray flames has been also investigated $[17,18]$. The use of low-swirl conditions for the main mixture flow allows to promote fuel-air mixing and to induce a controlled jet expansion which produces a velocity field where the flame front could be stabilized at a certain distance from the burner exit. As pointed out in such works, the potential in NOx reduction and the overall flame stability are strongly affected, respectively, by the fuel-air premixing occurring in the $\mathrm{LOH}$ and by the nature of flame confinement which would induce outer flow recirculation feeding hot gases at the flame base.

The main objective of the current work is to numerically investigate the low-swirl lifted flame configuration studied at KIT $[16,18]$ in order to support experimental findings regarding flame stabilization. The final outcome will be the definition of a suitable numerical modelling strategy to further develop lowswirl lifted flames for possible practical applications in actual GT combustors.

The numerical prediction of lifted flames has always represented a very challenging task for turbulent combustion CFD modelling, due to the necessity to accurately account for both finite rate chemistry and turbulent mixing. With particular reference to non-premixed jets, several fundamental DNS studies have been carried out in the last years $[19,20]$ supporting the understanding of lift-off mechanisms occurring in the triple flame configuration. When dealing with GT combustion, Large Eddy Simulation (LES) can be considered the state of the art for academic investigations and for detailed design steps at industrial level [21] being an effective compromise between physical consistency of adopted models and the applicability to the realistic cases. Several successful applications to lifted jet flames [22] and swirl stabilized flames can be found in the open literature [23]. The current study will exploit a standard LES commercial package to investigate the KIT low-swirl flame configuration: apart a first attempt due to Kern et al. [24] and the LES investigations available in [18], this work represents the first systematic attempt to setup a dedicated LES strategy to model this type of novel burner. As it will be discussed with more details later in this paper, turbulent combustion will be modelled by the means of the Flamelet Generated Manifold approach [25] where, in order to properly account for the effects of aerodynamic stretch and heat loss on the resulting turbulent flame speed (neglected in the baseline FGM approach), the strategies first suggested by TayWo-Chong et al. [26] for the Turbulent Flame Closure and then adapted to FGM by Klarmann et al. [27] are here generalized to LES framework and tested for the prediction of flame lift-off.

\section{TEST CASE: KIT LOW-SWIRL BURNER Description of investigated geometry}

A schematic representation of the low-swirl burner test rig investigated at KIT is reported in Figure 1: this concept has been investigated in different works in the last years [15-17]). In the current paper the latest investigations carried out by Sedlmaier and coworkers is taken as reference $[16,18]$. Nozzle was designed to operate with both liquid and gaseous fuels: only the natural gas operations will be considered in this work. Gas is introduced thanks to a dedicated slot, as shown in Figure 1: the injection location is just upstream of the prefilmer lip and the resulting angle is $35^{\circ}$ with a radially inward component of velocity. In turn, this slot is fed by a small plenum placed between the two swirlers bodies.

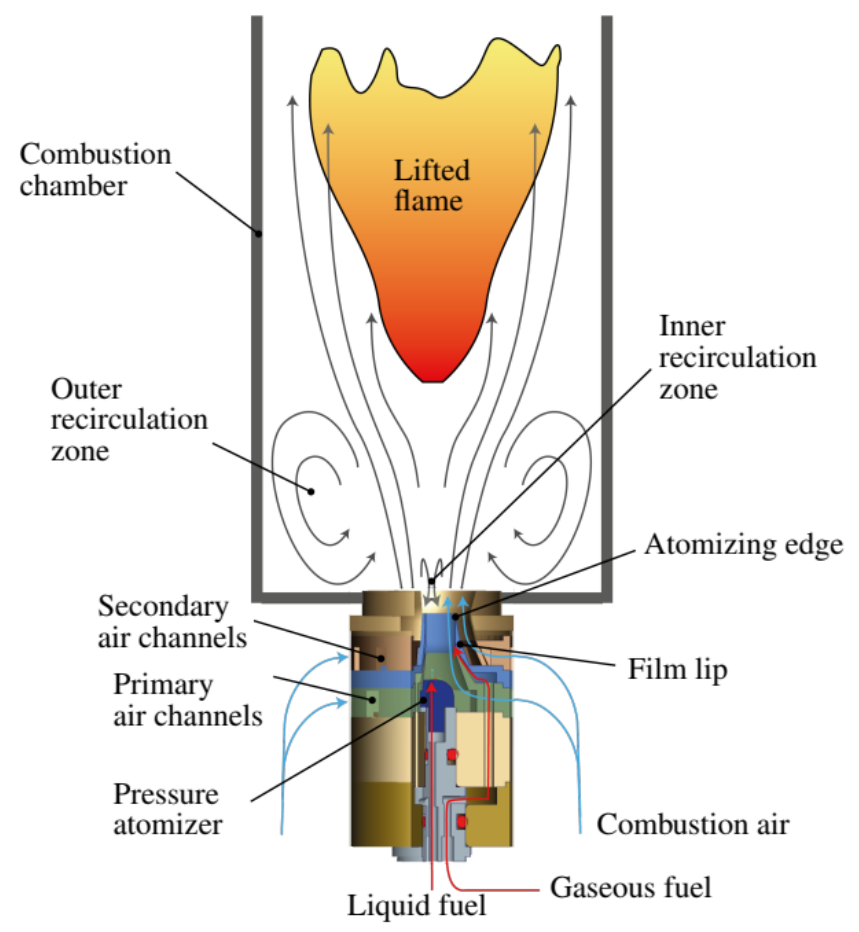

FIGURE 1. SKETCH OF THE INVESTIGATED RIG FROM [16].

The combustion air is collected in a plenum chamber placed upstream the nozzle, once being pressurized and preheated according to the specific operating conditions. Therefore, the air enters in the nozzle, where it is split between the two swirlers: the largest amount is delivered to the secondary channels, while the air passing through the primary one experiences a prelim- 
inary mixing with the fuel. The two air streams are gathered after the prefilmer lip edge in the nozzle diffuser, hence they are introduced in the flame tube. It is worthy to point out that a homogeneous premixing has yet not occurred at this position.

Overall low-swirl conditions at nozzle outlet are obtained by large difference in the swirl number imposed by primary and secondary channels. The considered swirl number, is defined as $S_{p}=\dot{D}_{i} /\left(R_{i} \dot{I}_{i}\right)$, being $\dot{D}_{i}$ the angular momentum flux, while $\dot{I}_{i}$ and $R_{i}$ are respectively the axial momentum flux and the inner radius of the prefilmer lip at the smallest section. Primary swirler has eight channels, where the swirl number assumes a value of $S_{p}=0.76$, while the secondary swirler, with twelve radial channels, has $S_{p} \approx 0$ : resulting overall $S_{p}$ is well below 0.4. The effective area of the nozzle is equal to $131 \mathrm{~mm}^{2} \pm 4 \mathrm{~mm}^{2}$.

The flame is confined in a cylindrical combustion chamber equipped with double-walled quartz-glass optical access. The overall length of the chamber is $320 \mathrm{~mm}$ (where $280 \mathrm{~mm}$ is the length of the optical window) and an inner diameter of $89 \mathrm{~mm}$. A constant cooling air flow is supplied into the walls cavity for such reactive tests employing methane. A preliminary quantification of the heat losses has been carried out by measuring the cooling air temperature at the cavity outlet and reported in [18].

A prior characterization of the flow-field coming from the nozzle has been carried out from isothermal operating conditions. LDA measurements are available both in terms of contours and velocity profiles for specific axial positions in the injector near field. It should be pointed out that this low swirled field results also in a low frequency precessing vortex core (a detailed description of such fluid phenomenon in combustion chamber can be found in [28]): for the cold flow conditions a frequency of $3-4 \mathrm{~Hz}$ has been identified by the authors and further data are available in [18].

The optical accesses allow the flame reaction zone visualization by $\mathrm{OH}^{*}$ chemiluminescence: the light emissions due to the thermally excited $\mathrm{OH}^{*}$ radicals are recorded by an intensified CCD camera with a chip maximum resolution of 1280x1024 pixels. The results are reported in terms of 2D time-averaged contour maps of $\mathrm{OH}^{*}$ emission intensity normalized respect to the maximum light emission value. These maps have been obtained by averaging 200 instantaneous images and it should be pointed out that they represent a line of sight integral of the light emissions on a plane. Further details on the experimental setup can be found in $[16,18]$.

\section{Experimental findings}

The low-swirl conditions of the flow issued by the nozzle produce a weak inner recirculation zone (IRZ) which is not observed to directly contribute to flame stabilization: its role is mainly to improve fuel/air mixing and to partly influence the flow field of the swirling jet promoting its diffusion. Sudden area expansion between nozzle outlet and chamber confinement walls induces an outer flow recirculation responsible of an upstream transport of hot combustion products in the early region of the main swirling jet. Thanks to such preheating and radicals contributions, the reactant mixture delivered by the nozzle, with more and more homogeneous composition flowing downstream, is able to develop a premixed-like flame front stabilizing at a liftoff height where an equilibrium with flow velocity is reached.

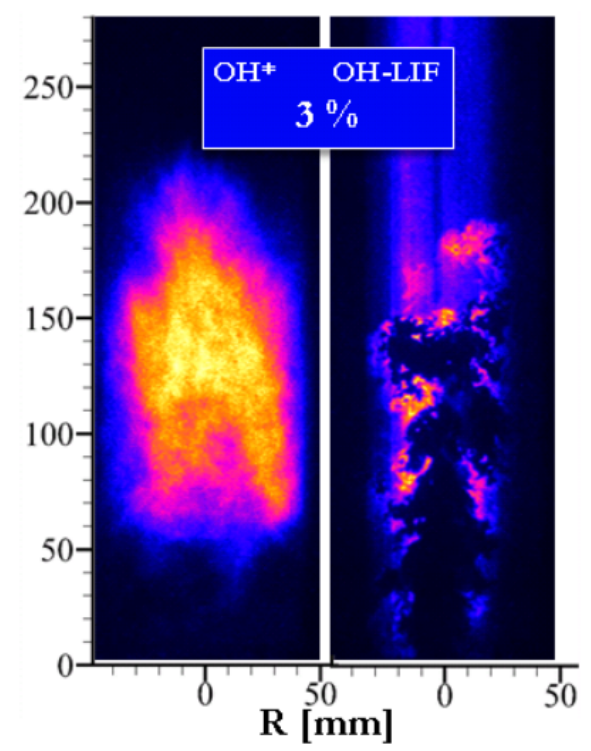

FIGURE 2. OH PLIF AND OH* CHEMILUMINESCENCE INSTANTANEOUS IMAGES (PRESSURE DROP 3\%) FROM [18].

The description of such stabilization mechanism is confirmed by the experimental investigations where a large and exhaustive set of sensitivity analyses have been carried out to point out the influence of main operating parameters such as inlet temperature, operating pressure, pressure drop across the nozzle and air-fuel equivalence ratio $\lambda$. Thanks to these studies, the following general conclusions about flame stabilization process can be drawn:

- Elevated temperatures at the jet base is observed to have a great impact on the flammability limits since they increase the laminar burning velocity significantly. This means that this kind of flame for this configuration has a higher resistance to lean blow-out;

- Four regions are observed in the flame: i) pre-combustion area, ii) combustion zone, iii) outer recirculation area, and iv) a post-flame region. Particularly interesting is the fact that the maximum temperature on the combustion zone corresponds to the $80 \%$ of the adiabatic temperature, while in the post-flame region the temperature approaches constant levels and equals the adiabatic combustion temperature. This fact points out that the combustion zone is experiencing a relevant heat loss, which should explain the low- 
ered reactivity occurring in the pre-combustion area, hence the lift-off of the flame;

- The recirculation of hot gases has a dominant role in the stabilization of the flame: when removing chamber confinement the flame cannot be stabilized in any operating conditions.

- The validity of a premixed-like stabilization process of the flame is confirmed by the absence of autoignition phenomena, at least with gaseous fuel. The observed flame front does not point out the typical triple flame structure suggesting an autoigntion process, while, as observed in Figure 2, the instantaneous concentration of $\mathrm{OH}$ provided by PLIF reveals pockets of reacting mixture in the early region of the swirling flow (pre-combustion area), despite local high flow velocity and extremely lean mixture do not allow flame to stabilize.

The available experimental results allow a qualitative and quantitative comparison with the numerical simulations in terms of flame morphology, as well as LOH values. It should be pointed out that a well-established definition of $\mathrm{LOH}$ in literature is not yet available, since many works are based on evaluation of the $\mathrm{OH}$ species concentration as indicator of the flame base, that is placed where this quantity exceeds a specified threshold value [23]. In this study, the lift-off height is defined as the location at which the intensity of chemiluminescence reaches the $10 \%$ of the entire reaction zone light intensity. This definition is preferred since it takes into account the hot main reaction zone, while simply considering hot combustion product concentration might be misleading due to the recirculation field near the nozzle exit [17].

\section{OVERALL CFD SETUP}

The spatially-filtered compressible Navier-Stokes equations have been solved with the Large Eddy Simulation (LES) approach using the solver ANSYS Fluent 2019-R1 [29]. The subgrid stress tensor due to the filtering operation has been closed through the Dynamic Smagorinsky-Lilly model [30] for its reliability and low computational cost. Both spatial and temporal second order numerical schemes have been adopted. The numerical simulations have been performed on two different conditions: an isothermal one, in order to characterize the injector flow-field behavior, and a reactive one. Since operating points are available for the reactive test case, as reported in [18], in the present work an operating pressure of 4 bar and a inlet air temperature of $573 \mathrm{~K}$ have been chosen. The adopted air mass flow has been derived from a relative pressure drop of $3 \%$ across the nozzle and considering the effective area measured during the isothermal campaign. The fuel flow has been obtained considering that the nominal $\lambda$ is equal to 1.91 for this operating point. The other operating conditions for both the simulations are re-
TABLE 1. OPERATING CONDITIONS USED IN CFD SIMULATIONS (SUBSCRIPT "0" USED FOR CONDITIONS AT AIR INLET).

\begin{tabular}{ccccc}
\hline Configuration & $p_{0}[\mathrm{bar}]$ & $T_{0}[\mathrm{~K}]$ & $\lambda[-]$ & $d P_{\text {nozzle }} / P[\%]$ \\
\hline Isothermal & 1 & 323 & - & 3 \\
Reactive & 4 & 573 & 1.91 & 3 \\
\hline
\end{tabular}

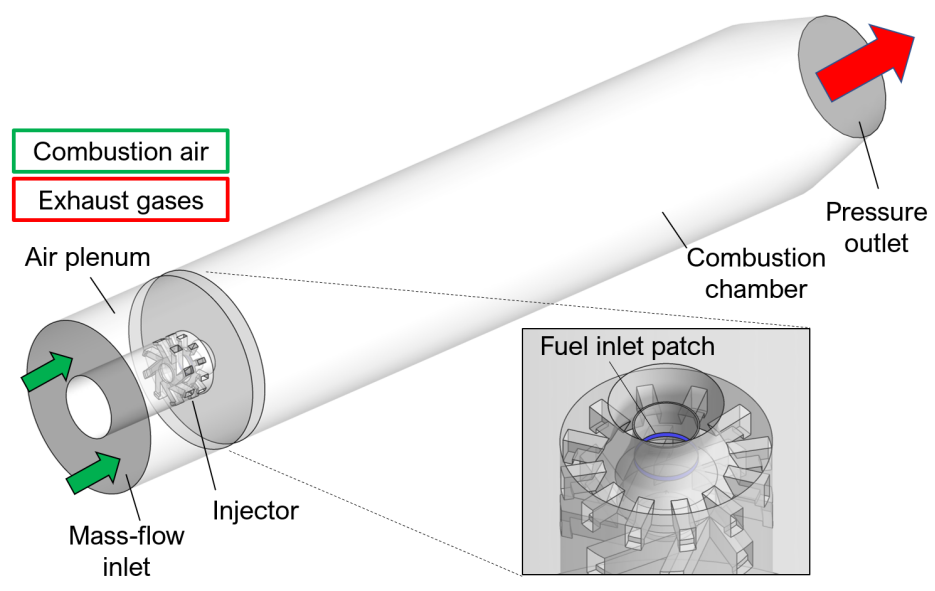

FIGURE 3. REPRESENTATION OF THE COMPUTATIONAL DOMAIN WITH THE DETAIL OF THE FUEL INJECTION PATCH.

sumed in Table 1. The numerical domain, shown in Figure 3, includes the entire flame tube with the aim of fully representing the unsteady turbulent effects in the combustion chamber. A cylindrical plenum has been added in order to simulate the air supply condition upstream the nozzle, as well as a convergent duct at the outlet for the exhaust tube.

A preliminary simulation has been performed for the reactive case on a coarse mesh (4M of tetrahedral elements) in order to test the modified combustion model, then applied on a refined grid corresponding to 10 millions of elements. From the coarse domain to the refined one, the number of elements within the nozzle diffuser diameter passes from 16 to 52. The isothermal simulation adopted a physical time step of $10^{-5} \mathrm{~s}$, while for the reactive simulation the value of the time step corresponds to $10^{-6} \mathrm{~s}$.

The final averaging time window covers a physical time of $0.2 s$ for the isothermal case, which corresponds to a approximately 8 times the Flow Through Time (FTT) of the first $100 \mathrm{~mm}$ of the combustion chamber, where the flame is positioned.

Regarding the reactive configuration, since two simulations have been performed, sampling times are respectively $0.12 s$ for the baseline FGM approach and $0.26 s$ for the modified version, respectively 4 and 9 times the estimated FTT for this reactive case. The opinion of the authors of the present work is that even 
a more extended sampling time for the classic FGM would not largely affect the final $\mathrm{LOH}$ value, as seen from the simulation on the coarse mesh. A longer sampling time would eventually influence only the flame tip morphology, while it should be very expensive in terms of computational resources. A possible reason for such requirement during the averaging procedure could be find in the presence of PVC observed during the preliminary isothermal experimental campaign. Although data are not available in this direction, its frequency seems not to be affected by the combustion process and its investigation will be an interesting point for future works.

Both configurations employ mass-flow inlet and pressure outlet as boundary conditions, as shown in Figure 3. Walls are modeled with no-slip conditions and a constant uniform negative heat flux has been imposed in the reactive configuration, according to the estimation of heat losses done in [18] for the specific operating condition. Five prismatic layers have been employed for the wall since a great influence of the wall is not expected for the turbulence field due to the type of nozzle injector.

\section{COMBUSTION MODELLING}

The turbulent combustion process was modelled using the Flamelet Generated Manifold (FGM) approach. This model describes the turbulent flame by tabulating laminar 1D flames in function of few control variables, here the mixture fraction $z$ and the progress variable $Y_{c}$, which describe completely the chemical state. While the mixture fraction traces the mixing of two separate streams, the progress variable represents the progress of the reaction toward equilibrium conditions. In this work the progress variable is defined as $Y_{c}=Y_{C O}+Y_{\mathrm{CO}_{2}}$. Typically, in a post-processing step, the progress variable $Y_{c}$ is normalized with the equilibrium mass fractions of the species, defining the normalized progress variable $c$ which is unity at equilibrium conditions.

In order to generate the flame manifold, premixed counterflow methane-air flamelets are solved for compositions varying from fuel to pure air using the GRI3.0 detailed reaction mechanism, with 325 reactions and 53 species. The thermo-chemical quantities are pre-integrated in a look-up table using presumed $\beta$-shaped probability density functions to take into account the turbulence-chemistry interaction. During the computation, four dedicated transport equations for the resolved un-normalized progress variable, mixture fraction and their variances are solved, allowing the interpolation of the thermo-chemical quantities from the table.

The quenching effects of flame stretch and heat loss were specifically introduced in the FGM model through the correction proposed by Klarmann et al. [27] in RANS framework. The model allows to account for the reduced reactivity due to local values of flame front deformation, which alters significantly all the diffusive processes of the reaction layer and enhance the sen- sitivity to heat losses. Within the FGM approach these effects can be related to a localized reduction of the mean progress variable source term $\overline{\dot{\omega}_{c}^{0}}$, i.e. the global reaction rate, which drives the turbulent flame propagation. Indeed, the model neglects the strain impact on the flame structure tabulated in the manifold, however it avoids adding further control variables and saves the computational efficiency of the model. The correction is formulated as [27]:

$$
\overline{\dot{\omega}_{c}}=\Gamma_{\kappa, \psi} \cdot \overline{\dot{\omega}_{c}^{0}}=\Gamma_{\kappa, \psi}(\kappa, \psi, z) \iint \dot{\omega}_{c}(z, c) P(z) P(c) d z d c
$$

where $\kappa$ is the flame stretch, $\psi$ the heat loss parameter and $\Gamma_{\kappa, \psi}$ the reduction factor of the progress variable source term tabulated in the manifold $\overline{\dot{\omega}_{c}^{0}}$.

The reduction factor can be expressed with laminar flame parameters, once provided particular hypotheses. Specifically, it is supposed that: (1) the stretch and heat loss have no qualitative influence on both the laminar flame front structure and turbulent modelled flame brush, i.e. only the progress variable source term, both laminar and average, is directly affected by the two phenomena, being scaled; (2) the sensitivity of the flame reactivity to stretch and heat loss does not depend on the level of turbulent fluctuation of $\mathrm{c}$ and $\mathrm{z}$. In other words, the stretch and heat loss have the same impact on the pdf-integrated source term for any value of the mixture fraction and progress variable variance. Taking (1) and (2), the reduction factor can be expressed in function of the consumption speed:

$$
\Gamma_{\kappa, \psi}(\kappa, \psi, z)=\left(\frac{S_{c}(\kappa, \psi, z)}{S_{c}^{0}(z)}\right)^{m} \in[0,1]
$$

with $S_{c}^{0}=S_{c}\left(\kappa=0, \psi_{a d}, z\right)$ being the unstretched adiabatic consumption speed and $m$ defined as:

$$
m \approx \frac{\log \left(\dot{\omega}_{c}^{\max }\left(\kappa, \psi_{0}, z_{0}\right)\right)}{\log \left(S_{c}\left(\kappa, \psi_{0}, z_{0}\right)\right)}
$$

The exponent $m$ can determined from laminar calculations of counter-flow premixed flames for one $\psi$ and $z$ varying the strain level, since a linear relationship between the maximum value of the progress variable source term $\dot{\omega}_{c}^{\max }$ and the fuel consumption speed was observed, similarly to the results in [27]. In the simulations, the laminar fuel consumption speed $S_{c}$ was computed as suggested by Poinsot and Veynante [31] by integrating the net fuel consumption rate across the flame.

For the definition of the reduction coefficient $\Gamma_{\kappa, \psi}$ (Eq. 2), the consumption speed distribution as a function of stretch, heat loss and mixture fraction is needed. Generally, in addition to those parameters, the laminar consumption speed also depends on different quantities such as the fuel species, the reaction mechanism, the fresh mixture temperature and the operating pressure. This complex dependence has still to be described analytically, 
except for particular validity ranges, as in [26]. Nevertheless, fixing the fuel blend and the fresh mixture conditions, the consumption speed can be computed and tabulated in function of the other parameters, i.e. the stretch, the heat loss and the mixture fraction. Although the use of a correlation would avoid the evaluation of $S_{c}$, the development of a tabulation strategy allows to arbitrary analyse conditions of interest.

In this work, a look-up table for the fuel consumption speed was populated in a dedicated pre-process to enable the computation of the reduction coefficient $\Gamma_{\kappa, \psi}$ during the simulation. The local values of flame stretch and heat loss, not provided by the baseline FGM, are modelled and calculated at runtime, allowing the query of the $S_{c}$ look-up table to evaluate $\Gamma_{\kappa, \psi}$. Finally, the coefficient is applied to the uncorrected progress variable source term, which is retrieved from the FGM table. The next section will be focused on the pre-process to tabulate the consumption speed from laminar calculations. The FGM model corrected with the factor $\Gamma_{\kappa, \psi}$ will be referred hereafter as FGM-EXT.

\section{Consumption Speed Tabulation}

The evaluation of the factor in Eq. 2 requires as input the consumption speed value depending on the flame stretch, heat loss and mixture fraction. A script in Python language was integrated with the Cantera v2.4.0 libraries [32] to solve in parallel one-dimensional laminar flames in premixed counterflow configuration, i.e. fresh to equilibrium products opposed jets.

For all the simulations the pressure was set accordingly to the desired operating conditions to $p=388000 \mathrm{~Pa}$ and the fresh temperature determined by the mixing of pure air at $T_{o x}=573 \mathrm{~K}$ and methane at $T_{f}=300 \mathrm{~K}$, according to $T=z T_{f}+(1-z) T_{o x}$. Then, the mixture fraction, the flame strain and the products temperature were varied independently. For each flamelet the laminar consumption speed was computed and stored in function of mixture fraction, stretch and of $\psi=T_{b} / T_{e q}$, namely the heat loss correction. Note that this definition of $\psi$ is different from the one of Klarmann et al. [27], but represents the same departure from the adiabatic temperature for heat losses.

Globally, roughly 16,000 flames were solved. The computed consumption speed values $S_{c}$ were then linearly interpolated in a finer regular grid of $Z \times \psi \times a=293 \times 44 \times 200$ points, in order to reduce the discretization error during the table query.

In Figure 4 a visualization of the look-up table showing the values at a single representative mixture fraction as a function of strain and heat loss is presented.

At the start of the CFD simulation, a dedicated sub-routine in $\mathrm{C}$ language was exploited to load the look-up table in RAM memory, allowing the random access by the solver using the values of stretch $\kappa$, heat loss $\psi$, and mixture fraction $z$. The specific computation of the quenching effects in LES is detailed in the following section.

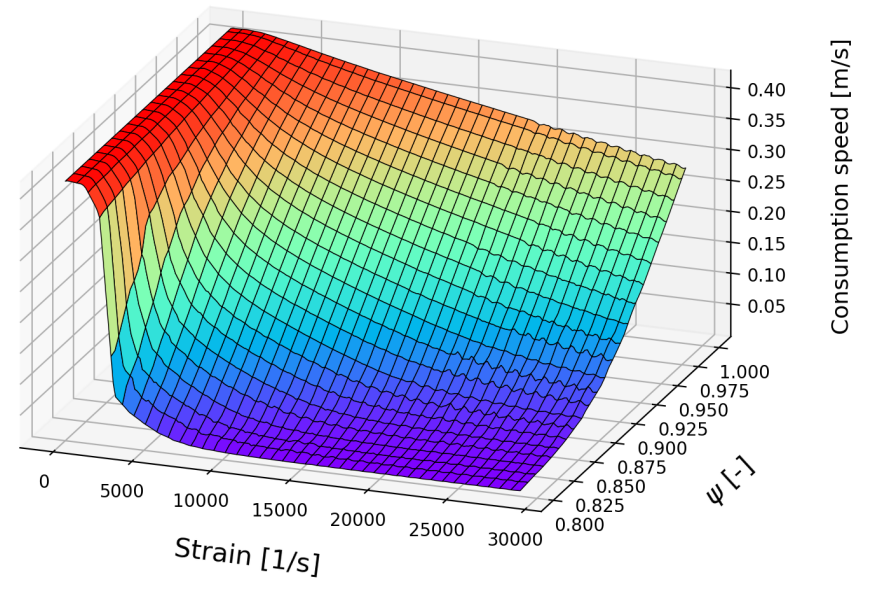

FIGURE 4. CONSUMPTION SPEED DEPENDENCE ON STRAIN AND HEAT LOSS FOR A MIXTURE FRACTION OF 0.040.

\section{Stretch and Heat Loss Modelling}

Despite the model was originally proposed in RANS framework, the rationale behind it can be extended to LES without particular modifications. However, the two approaches deeply differ in the flame stretch modelling, which was here inspired by previous works focused on the Turbulent Flame Closure [33-35]. The present work represents the extension of the Klarmann's model [27] to Large Eddy Simulation, adopting and improving the quenching effects formulation in [33-35] thanks to the modelling of the front curvature contribution on the flame stretch.

Assuming a thin front the flame stretch $\kappa$, i.e. the rate of the flame surface variation per unit area, is defined as [31]:

$$
\kappa=\frac{1}{A} \frac{d A}{d t}=\left(\delta_{i j}-n_{i} n_{j}\right) \frac{\partial u_{i}}{\partial x_{j}}+S_{l} \frac{\partial n_{i}}{\partial x_{i}}=a+\sigma_{c}
$$

where $A$ is the flame surface, $\delta_{i j}$ is the Kronecker delta, $n$ is the unit vector normal to the front and $S_{l}$ the laminar flame speed. The stretch is thus due to the separate contribution of flame strain $a$, i.e. the fluid strain rate tangential to the flame front, and the curvature of the flame front $\sigma_{c}$.

In LES framework, the above definition can be filtered and the two terms of $a$ and curvature $\sigma_{c}$ distinguished. Applying the filter to the strain definition leads to [33]:

$$
\tilde{a}=\left(\delta_{i j}-\widetilde{n_{i} n_{j}}\right) \frac{\partial \widetilde{u}_{i}}{\partial x_{j}}+\left[\left(\delta_{i j}-n_{i} n_{j}\right) \frac{\partial u_{i}^{\prime}}{\partial x_{j}}\right]=\widetilde{a}_{r e s}+\widetilde{a}_{s g s}
$$

The filtered strain is thus evaluated as sum of the strain induced by the resolved and sub-grid flow structures.

The resolved part can be extrapolated from the fluid strain rate, removing the component normal to the flame. This operation can be carried out by computing the flame front normal unit vector from the progress variable $\tilde{c}$ field as: 


$$
n=-\frac{\nabla \tilde{c}}{\|\nabla \tilde{c}\|}
$$

The other contribution to total strain (Eq. 5) is the part associated to the sub-grid turbulent motions, which requires specific modellings. In this work, it is expressed in terms of the sub-grid time scale and corrected with an efficiency function $\Pi_{k}$ :

$$
\widetilde{a}_{s g s}=\frac{\Pi_{k}}{\tau_{\Delta}}
$$

The correction $\Pi_{k}$ accounts for the reduced influence of the smallest turbulent eddies to strain the flame front because their lifetime is not long enough to affect significantly the combustion process. By fitting DNS data, Meneveau et al. [36] proposed the following formulation for the efficiency function:

$$
\begin{gathered}
\log _{10} \Pi_{k}=-\frac{1}{s+0.4} e^{-(s+0.4)}+\left(1-e^{-(s+0.4)}\right)(s \sigma-0.11) \\
s=\log _{10}\left(\frac{\Delta}{\delta_{l}^{0}}\right), \quad \sigma=\frac{2}{3}\left(1-\frac{1}{2} \exp \left[-\left(\frac{u_{\Delta}^{\prime}}{S_{c}^{0}}\right)^{\frac{1}{3}}\right]\right)
\end{gathered}
$$

where $\delta_{l}^{0}$ and $S_{c}^{0}$ stand for the unstretched laminar flame front thickness and consumption speed respectively and $u_{\Delta}^{\prime}$ the subgrid velocity fluctuation, modeled as:

$$
u_{\Delta}^{\prime}=\frac{v_{t}}{C_{s} \Delta}
$$

Combining the set of Eqs. 5-9 the local strain of the flame front can be evaluated at any time. Nevertheless, the flame stretch definition requires the calculation of the front curvature $\sigma_{c}$. Despite in previous LES studies it was not modelled [33-35,37], in this work this contribution was included by filtering its definition:

$$
\widetilde{\sigma}_{c}=S_{c}^{0} \frac{\partial \tilde{n}_{i}}{\partial x_{i}}=S_{c}^{0} \nabla \cdot \tilde{n}
$$

Note that the unstretched laminar consumption speed is considered among the different laminar flame speed definitions. The curvature contribution is algebraically added to the strain to evaluate the flame stretch, which is then clipped to zero consistently to the non-negative values recorded in the laminar database.

Concerning the heat loss, no specific modelling is required, but still there is the need to extend the validity of the tabulation parameter $\psi$ to the LES-FGM framework. Indeed, $\psi$ is defined in the products of laminar counterflow flamelets, i.e. for $c=1$ and $c^{\prime \prime 2}=0$. In the FGM approach it should be well-defined for all the progress variable field, so it is expressed as the ratio of the local temperature to the local adiabatic temperature:

$$
\psi=\frac{T_{b}}{T_{e q}} \simeq \frac{T\left(\tilde{z}, \tilde{z}^{\prime \prime 2}, \tilde{c}, \tilde{c}^{\prime \prime 2}, \tilde{h}\right)}{T_{a d}\left(\tilde{z}, \tilde{z}^{\prime \prime 2}, \tilde{c}, \tilde{c}^{\prime \prime 2}, \tilde{h}_{a d}\right)}
$$

Thanks to this formulation, the exact definition is retrieved in the products where $c=1$. It is important to stress that the $\psi$ coefficient reported above is different from the heat loss parameter used by Klarmann et al. [27], who preferred instead an enthalpy defect. However, the authors consider the two approaches equivalent in the framework of non-adiabatic FGM, since the thermochemical quantities are tabulated in the manifold in function of the enthalpy defect with respect to adiabatic conditions.

The Eqs. 5-12 are implemented in ANSYS Fluent as a UserDefined Function and evaluated within the main solver cell loop for each time-step. The stretch $\kappa$ and the heat loss correction $\psi$ are then used to read the local value of the consumption speed from the table.

\section{RESULTS \\ Isothermal case}

Three different axial positions have been considered for the velocity profiles extraction and circumferentially averaged both for the coarse and fine mesh. In Figure 5 is reported the comparison between numerical simulation and experimental data for the axial and tangential component, in terms of both mean values and velocity fluctuations. Here only the profiles for the finer mesh are reported for the sake of brevity. Similarly, the radial component is not reported since its low magnitude respect to the other components.

Results are in good agreement with the experimental data for the axial component, showing an appropriate representation of the characteristic flow-field of the nozzle. It clearly pointed out the limited aperture of the annular jet as a consequence of the low swirl number. Swirling jet penetrate maintaining the radial location of its peak velocity within $10 \mathrm{~mm}$ : at higher radii the velocity decays to slightly negative values, leading to the characteristic outer recirculation zone. Also the IRZ is well reproduced, with its reduced extension both in terms of axial and radial positions, as expected for this type of injector. Regarding the axial velocity fluctuations it can be seen that the larger values can be found again in the inner region within $15 \mathrm{~mm}$, with the presence of a main fluctuations peak and a second lower one, hence decaying moving towards the outer recirculation zone. Here, the second peak is slightly underestimated by the numerical simulation, especially for the closest axial positions.

Considering the mean tangential component of velocity, it can be seen its overall lower magnitude respect to the axial one. Similarly to the axial component, a peak of velocity can be found in inner regions, followed by almost zero values between 7 and $10 \mathrm{~mm}$, due to the presence of the non-swirled air steams outgoing from the secondary channels. In the outer recirculation zone, this component is slowly decaying, but still maintain the same orientation of the swirling flow of the inner region. For this component, the numerical results are showing a quite good agreement with the experimental data, showing only an overall small underestimation of the peak in the inner region. Instead, considering the tangential velocity fluctuations a general lack of accuracy is present: the magnitude of the fluctuations are generally underes- 

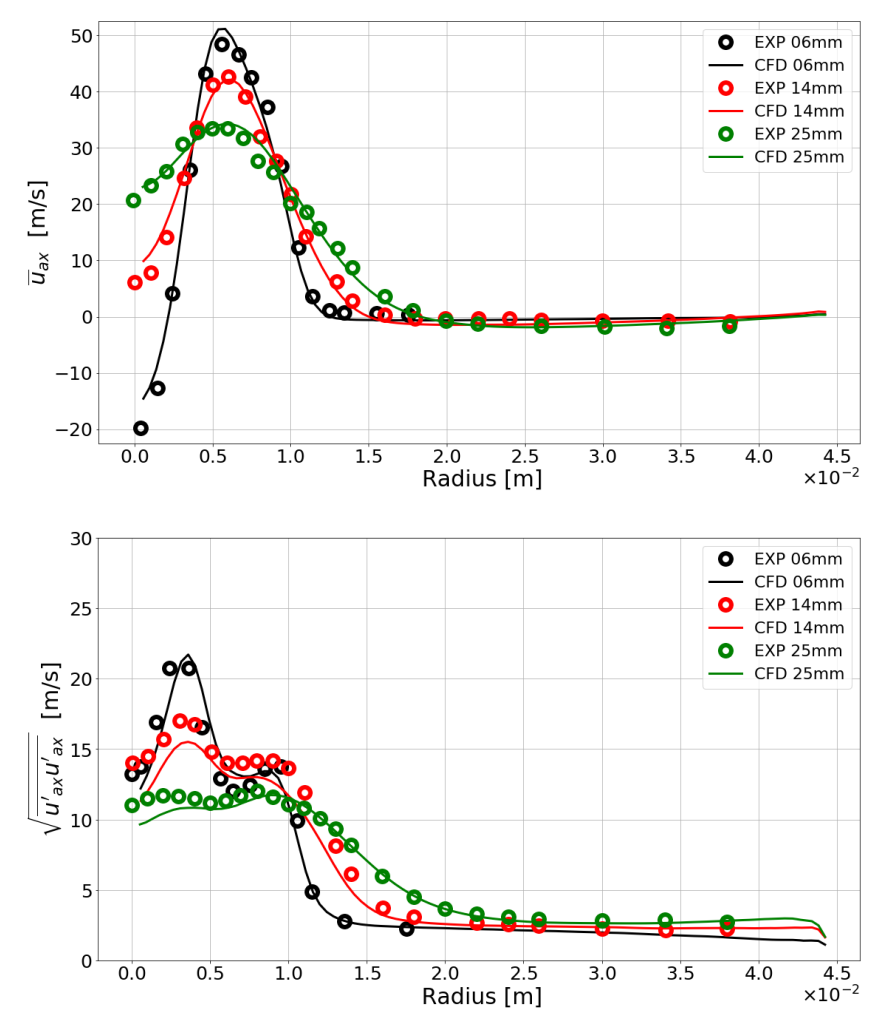
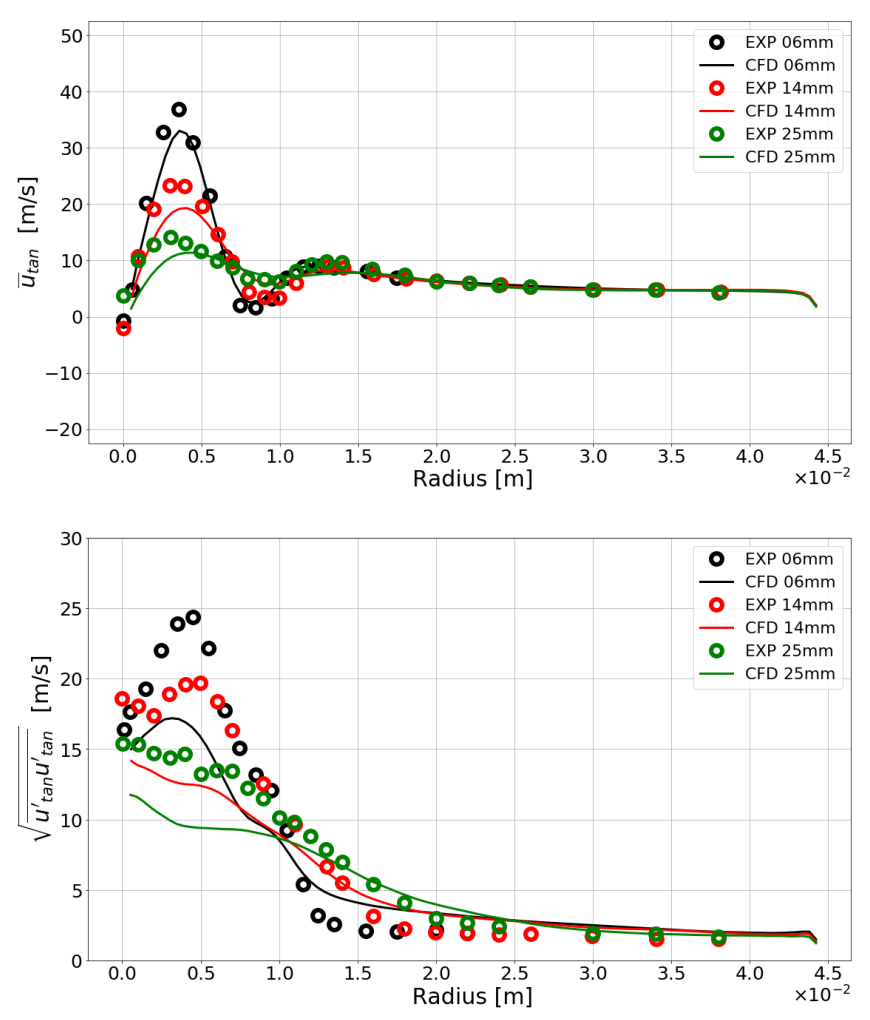

FIGURE 5. ISOTHERMAL CASE: COMPARISON BETWEEN NUMERICAL AND EXPERIMENTAL DATA FOR THE AXIAL AND TANGENTIAL MEAN COMPONENT AND FLUCTUATIONS OF VELOCITY. TANGENTIAL AVERAGED PROFILES FOR GIVEN POSITIONS.

timated and the trend is not correctly represented, especially the fluctuations peaks in the inner region within $15 \mathrm{~mm}$.

A possible explanation for this results can be addressed to a not proper discretization of this region of the flow, pointing out that a more refined mesh should be employed within the nozzle and its near field. Nonetheless, considering the still high computational cost for the isothermal simulation and a substantially quite good agreement regarding the mean velocity component, these results can be considered acceptably good for the further reactive simulation. Investigation on this lack of turbulent components is left to further works in order to better understand their influence.

\section{Reactive case}

The flame morphology provided by the experimental campaign is reported in Figure 6 as line-of-sight integrated maps of $\mathrm{OH}^{*}$ chemiluminescence: values are normalized over the maximum intensity recorded for each specific test. In the numerical simulations, a similar procedure is applied to the source term of the progress variable per unit mass for the baseline FGM approach and the extended version (FGM-EXT). This quantity can be seen as indicator of the ongoing reaction and in the present work is used in a comparison with the experimental images of $\mathrm{OH}^{*}$. Such comparison provides from a qualitative point of view the shape of the flame, giving an information of its extension and allowing the evaluation of the $\mathrm{LOH}$ value according to the aforementioned definition given in $[16,17]$.

Superimposed to flame maps, Figure 6 shows the values of LOH by measured data (EXP), the baseline FGM and the corrected version (FGM-EXT). The measured LOH of $70 \mathrm{~mm}$ is underpredicted by both numerical models predicting respectively $36 \mathrm{~mm}$ and $46 \mathrm{~mm}$. The underestimation of the $\mathrm{LOH}$ is a result of the reactivity over-prediction with respect to the real physics of the problem, which results in a flame stabilizing more upstream to the expected position. This fact is also confirmed by the shape of the flame: the numerical approaches show a reduced length of the flame both in the axial and radial direction, while from the experimental contours, the flame is far longer and reaches the confinement walls. Nonetheless, the use of the stretch and heat loss correction allows a prediction closer to the experimentally observed flame shape and an increased value of the $\mathrm{LOH}$ compared to the classic approach. This implies the importance of including quenching effects for a correct representation of the flame.

Despite the underprediction of the $\mathrm{LOH}$, the adopted numer- 


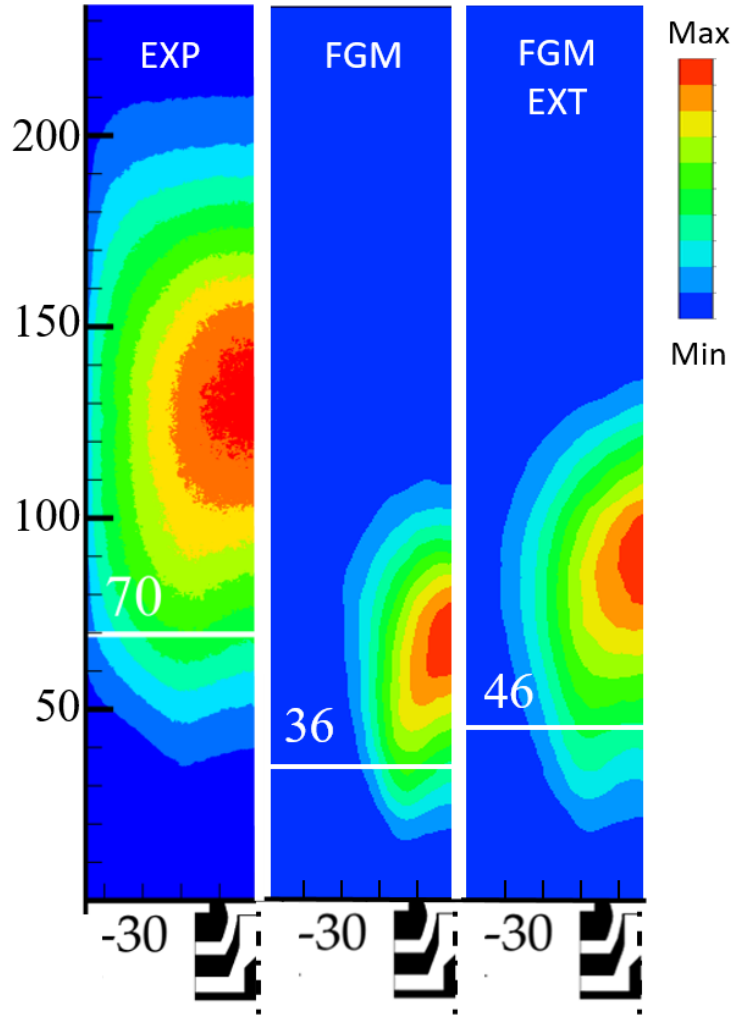

FIGURE 6. COMPARISON (LINE OF SIGHT INTEGRAL) AMONG EXPERIMENTAL OH* EMISSION INTENSITY MAP [18] AND PFR MAPS OBTAINED FROM THE UNMODIFIED FGM APPROACH AND THE CORRECTED APPROACH. THE NUMBER IN THE FIGURES STANDS FOR THE LOH VALUE IN $\mathrm{mm}$.

ical setup seems to successfully predict the dynamic behaviour of the flame and its stabilization mechanism. To support the first point, the instantaneous value of the $\mathrm{LOH}$ were sampled during LES statistics convergence with the aim of computing the Probability Density Function (PDF) of such quantity (see Figure 7). The obtained distribution is not far from a Gaussian centered around the mean value of the computed LOH (46 mm). Distribution extends from $32 \mathrm{~mm}$ to $52 \mathrm{~mm}$ resulting in $\mathrm{LOH}$ fluctuations amplitude around the mean value of about $10 \mathrm{~mm}$. This result is extremely interesting if compared to the outcomes of the experimental study done by Cessou [38] on lifted-flames issuing from a methane jet, where LOH fluctuations have been found of the same order of the large scale structures. In the current flow field it can be argued that the largest turbulent flow structures are aligned with the inner diameter of the swirler which is exactly $10 \mathrm{~mm}$.

Concerning the prediction of the stabilization process, a set of comprehensive contour maps are reported in Figure 8. Considering the flame leading edge (labeled with A in Figure 8), it can be seen that its time-averaged position occurs on the outer

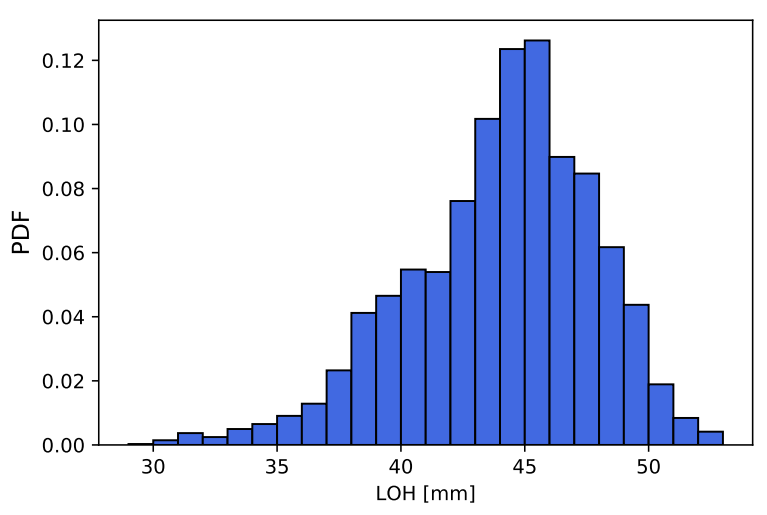

FIGURE 7. PROBABILITY DENSITY FUNCTION (PDF) OF LOH FOR THE CONSIDERED OPERATING CONDITIONS.

side of the swirling jet shear layer, in a fairly premixed region, where hot combustion products recirculate upstream and allow the flame stabilization. The outer recirculation zone is therefore responsible of the leading edge anchoring in a lean region of the mixture fraction field, in agreement with the experimental observations. Meanwhile, the inner zone of the jet (label B) presents high velocity magnitudes, which push the flame front downstream notwithstanding the local richer mixture fraction. Starting from the flame leading edge and moving downstream, the flame follows the expansion of the jet stream in the radial direction (label $\mathrm{C}$ ): here, the first non-negligible progress variable source term isoline is located along the zero axial velocity isoline. In this region, the hot combustion products operate a continuous re-ignition process of the fresh mixture, as pointed out in the experimental OH-PLIF images (Figure 2), as well as of the previously quenched gas pockets. The combustion process is then completed and the two isolines separates before reaching the confinement wall.

Further discussions can be drawn looking to the averaged flow-fields, reported for both the approaches in Figure 8, in terms of axial velocity, mixture fraction and static temperature. Here, the isolines of normalized source term of the progress variable per unit mass are superimposed on the iso-contours, in order to show the flame position on that plane. Additionally, the axial velocity iso-contours reports also the velocity vector field, while only the zero axial velocity isoline is present on the mixture fraction and temperature contours. Finally, each of those report on the left side the results coming from the original FGM approach and the ones from the extended approach on the right.

These results hence confirm that the fundamental stabilization mechanism pointed out from the experimental campaign is caught with both the combustion models, while a probable cause of the wrong $\mathrm{LOH}$ prediction be due to a low magnitude of the stretch and heat loss effects. Figure 9 reports the averaged fields 

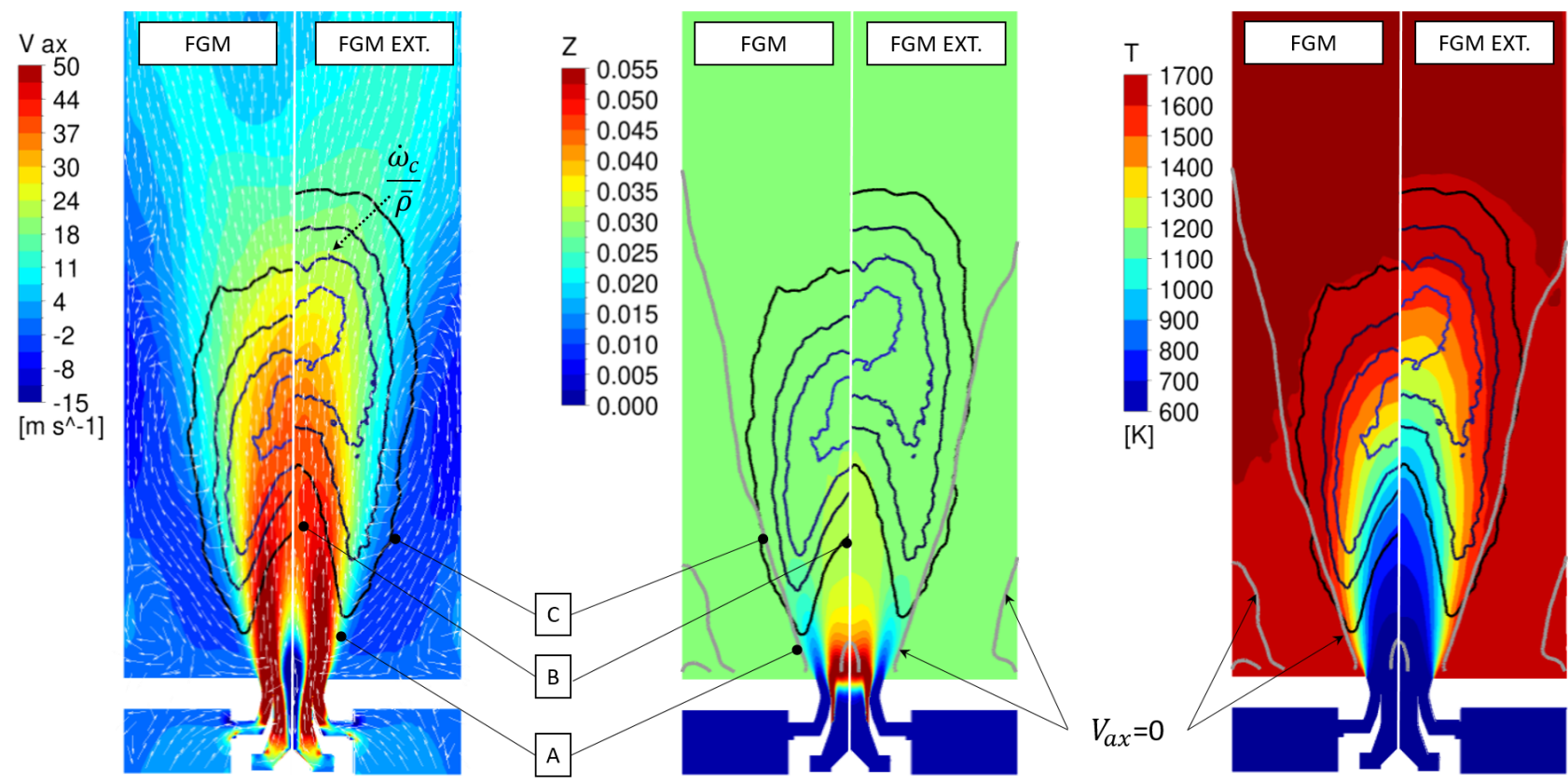

FIGURE 8. CONTOURS OF MEAN AXIAL VELOCITY (LEFT), MEAN MIXTURE FRACTION (MID) AND MEAN TEMPERATURE (RIGHT) IN REACTIVE CASE. THE SOLID GREY LINE STANDS FOR THE ZERO AXIAL VELOCITY ISOLINE WHILE THE PV SOURCE ISOLINES ARE REPORTED FOR THE FLAME VISUALIZATION.

of each contributes which lead to the correction factor, in order to see separately how they are influencing the flame. In this picture only the first part of the combustion chamber is reported, in order to focus on the effects at the flame base position. It is important to stress that these quantities assume physical meaning only within the flame brush: the reaction progress isoline for a value of 0.9 is reported in order to evaluate the correction factor value where the reaction is likely to occur. The correction factor $\Gamma_{k}$ assumes low values in the central region of the jet, while moves close to unity in the jet shear layer. This implies a lowered reactivity in the inner region, while the correction effects are less important in the outer recirculation zone promoting the stabilization. Since an increase of $\mathrm{LOH}$ will be related to a wider region of low $\Gamma_{k}$, it is worthy to look singularly to the main contribute of the correction factor. The stretch map in Figure 9 clearly shows its strong influence in the core of the jet, leading to low $\Gamma_{k}$ values in this region, while it presents low values within the outer recirculation zone. Considering its components, the modeled strain play a major role either respect to the resolved part and the curvature. Strain shows the maximum magnitude near the injector exit, where the larger turbulent fluctuations are present and the sub-grid scales contributes is relevant. Regarding the curvature, its value is two orders of magnitude smaller than the strain, showing in this case a very marginal effect on the final stretch prediction. According to the authors, the employment of a further refined mesh will lead to a better discretization of the flame front and therefore to a more representative values. Moreover, a more refined mesh should also allows a better description of the turbulent fluctuations which are described by the sub-grid strain model and could explain the disparity between resolved and modeled strain. As a matter of fact, it is expected that smaller elements will change the relative weight of sub-grid strain in favor of the resolved part, which is expected to be more accurate since it does not involve complex modellings.

The heat loss instead is showing a very poor contribution in the pre-combustion zone: its value does not fall below 0.97 in the region of interest for the flame stabilization, while slightly lower values can be found in the corners of the confinement walls. Its magnitude is related to the heat flux imposed at the boundary, in order to take into account the combustion chamber heat losses through the confinement. As already explained, in the current study a constant negative heat flux on the walls is imposed, where its magnitude has been derived from the information available in [18], reported as percentage loss of the nominal thermal power for the specific test point. This is clearly a strong assumption respect to the real heat transfer of the combustion chamber, where a not uniform heat flux on the wall is expected other than a contribute of flame radiation. Including these effects could lead to a cooler combustion products recirculation, hence affecting the flame leading edge position. These considerations are further supported considering the dependence of $\Gamma_{k}$ on heat loss for a fixed mixture fraction and fixed strain values, reported in Figure 


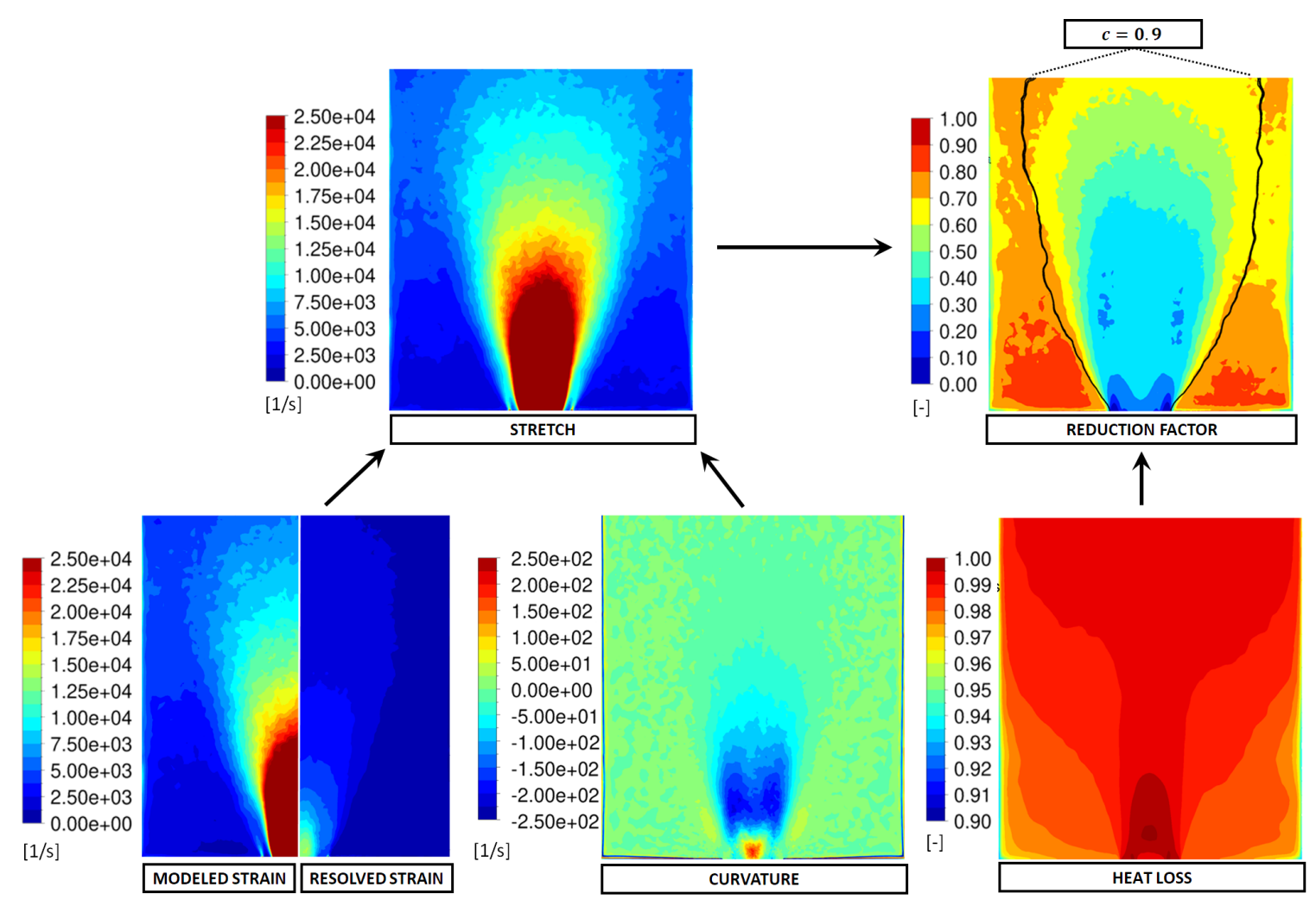

FIGURE 9. MAPS OF THE TIME-AVERAGED QUENCHING EFFECTS AND THEIR CONTRIBUTIONS FOR FGM-EXT IN THE NOZZLE NEAR-FIELD.

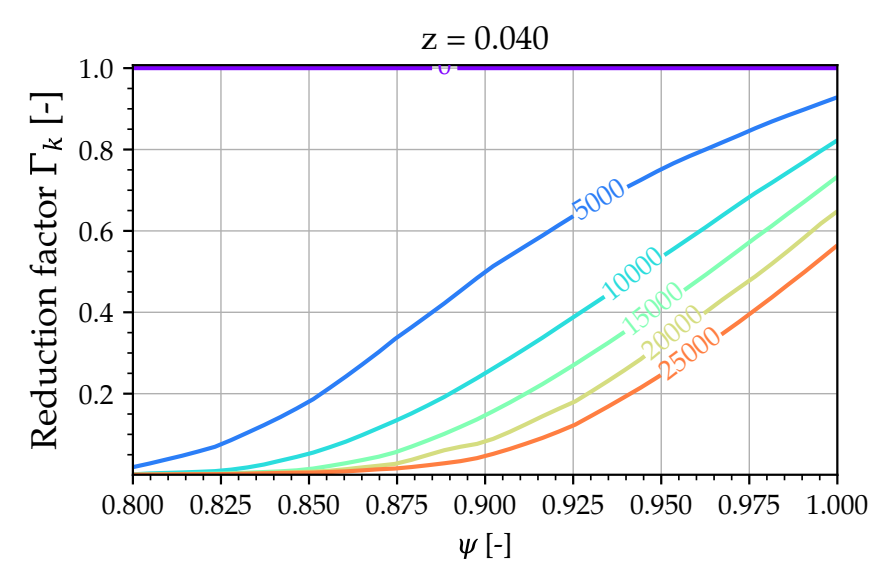

FIGURE 10. REDUCTION FACTOR $\Gamma_{k}$ VARYING HEAT LOSS FOR DIFFERENT VALUES OF STRAIN (1/s UNITS) FOR z=0.040.

10. This plot shows how for the strain values observed in the flame stabilization region, the variation of $\Gamma_{k}$ in function of $\psi$ is very rapid: considering the strain values in the flame leading edge, even a modest decrease of $\psi$ could lead to a large decrease of the the correction factor, which directly reduces the local reactivity, eventually quenching the flame. This high sensibility is expected to have a major influence on the flame anchoring positions in the external shear layer, justifying the strong impact of the recirculation zones observed experimentally.

Concluding, the opinion of the authors is that by applying more realistic thermal boundary conditions to the combustion chamber walls will lead to a significant improvement of the FGM-EXT approach results. This step, together with a mesh refinement, will be object of future investigations.

\section{CONCLUSIONS}

In the present work, a low-swirl partially premixed liftedflame investigated at KIT $[16,18]$ has been modeled thanks to an FGM approach taking into account the flame quenching effects of stretch and heat loss. The model proposed by Klarmann [27] in RANS has been extended to LES framework adapting the stretch and heat loss modelling and including the flame front curvature. A numerical simulation has been performed on a numerical domain representative of the combustion chamber employed in the experimental campaign. The result has been compared to the available data in terms of flame shape and liftoff height $(\mathrm{LOH})$ value, showing a substantial underestimation of this value respect to the experimental data. However, an im- 
provement with respect to the value predicted by the baseline FGM approach has been observed, both in terms oh LOH values and flame shape. Moreover, the main stabilization mechanism, that is the establishment of an outer recirculation moving hot gases and reactive radicals upstream to the jet base, seems to be caught by both the models. Keeping in mind these aspects, the extended model seems to effectively reproduce properly the local quenching effects, but nonetheless the main issue remain the correct modelling of the leading causes behind these effects.

For this reason, future works should focus on the employment of finer mesh grid for better describing the aerodynamic strain, as well as the flame front curvature effects. Another point is the poor influence of heat loss effects on the flame front position shown in the numerical model. This point rely on the few information available for the thermal boundary conditions at the confinement walls: a preliminary estimation of such losses has been employed to model a constant heat flux, uniformly distributed on the walls. This scenario is hardly representative of the real test case and this is probably one of the major limit of the present numerical setup. This aspect is particularly crucial considering that the recirculating combustion products temperature is fundamental for the flame base position. More detailed information in this sense, especially regarding the confinement walls placed upstream of the flame front, could lead to a further improvement of the $\mathrm{LOH}$ estimation.

\section{ACKNOWLEDGMENT}

This project has received funding from the Clean Sky 2 Joint Undertaking (JU) under grant agreement N. 831881 (CHAiRLIFT). The JU receives support from the European Union's Horizon 2020 research and innovation programme and the Clean Sky $2 \mathrm{JU}$ members other than the Union.

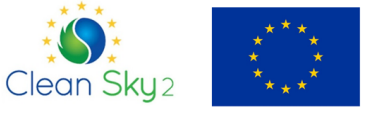

Prof. W. Polifke and Dr. L. Tay-Wo-Chong are also gratefully acknowledged for the useful suggestions regarding the calculation of the strain rate. The authors acknowledge the CINECA award under the ISCRA initiative (ISCRA C "SHELL" project), for the availability of high performance computing resources.

\section{REFERENCES}

[1] Meier, W., Duan, X., and Weigand, P., 2005. "Reaction zone structures and mixing characteristics of partially premixed swirling ch4/air flames in a gas turbine model com- bustor". Proceedings of the Combustion Institute, 30(1), pp. $835-842$.

[2] Marinov, S., Kern, M., Merkle, K., Zarzalis, N., Peschiulli, A., and Turrini, F., 2010. "On swirl stabilized flame characteristics near the weak extinction limit". ASME Conference Proceedings(GT2010-22335).

[3] Benard, P., Lartigue, G., Moureau, V., and Mercier, R., 2019. "Large-eddy simulation of the lean-premixed preccinsta burner with wall heat loss". Proceedings of the Combustion Institute, 37(4), pp. 5233 - 5243.

[4] Innocenti, A., Andreini, A., Facchini, B., Cerutti, M., Ceccherini, G., and Riccio, G., 2016. "Design improvement survey for nox emissions reduction of a heavy-duty gas turbine partially premixed fuel nozzle operating with natural gas: Numerical assessment". Journal of Engineering for Gas Turbines and Power, 138(1).

[5] Wohl, K., Kapp, N. M., and Gazley, C., 1948. "The stability of open flames". In Symposium on Combustion and Flame, and Explosion Phenomena, Vol. 3, Elsevier, pp. 3-21.

[6] Lyons, K. M., 2007. "Toward an understanding of the stabilization mechanisms of lifted turbulent jet flames: experiments". Progress in Energy and Combustion Science, 33(2), pp. 211-231.

[7] Vanquickenborne, L., and Van Tiggelen, A., 1966. "The stabilization mechanism of lifted diffusion flames". Combustion and Flame, 10(1), pp. 59-69.

[8] Buckmaster, J., 2002. "Edge-flames". Progress in Energy and Combustion Science, 28(5), pp. 435-475.

[9] Buckmaster, J., and Weber, R., 1996. "Edge-flameholding". In Symposium (International) on Combustion, Vol. 26, Elsevier, pp. 1143-1149.

[10] Miake-Lye, R. C., and Hammer, J. A., 1989. "Lifted turbulent jet flames: a stability criterion based on the jet largescale structure". In Symposium (International) on Combustion, Vol. 22, Elsevier, pp. 817-824.

[11] Peters, N., and Williams, F. A., 1983. "Liftoff characteristics of turbulent jet diffusion flames". AIAA journal, 21(3), pp. 423-429.

[12] Cheng, R. K., et al., 2006. "Low swirl combustion". The Gas Turbine Handbook, pp. 241-255.

[13] Littlejohn, D., Cheng, R. K., Noble, D., and Lieuwen, T., 2010. "Laboratory investigations of low-swirl injectors operating with syngases". Journal of Engineering for Gas Turbines and Power, 132(1).

[14] Day, M., Tachibana, S., Bell, J., Lijewski, M., Beckner, V., and Cheng, R. K., 2012. "A combined computational and experimental characterization of lean premixed turbulent low swirl laboratory flames: I. methane flames". Combustion and Flame, 159(1), pp. 275-290.

[15] Fokaides, P. A., Kasabov, P., and Zarzalis, N., 2008. "Experimental investigation of the stability mechanism and emissions of a lifted swirl nonpremixed flame". Jour- 
nal of Engineering for Gas Turbines and Power, 130(1), p. 011508.

[16] Sedlmaier, J., Habisreuther, P., Zarzalis, N., and Jansohn, P., 2014. "Influence of liquid and gaseous fuel on lifted flames at elevated pressure stabilized by outer recirculation”. In ASME Turbo Expo 2014: Turbine Technical Conference and Exposition, American Society of Mechanical Engineers Digital Collection.

[17] Kasabov, P., Zarzalis, N., and Habisreuther, P., 2013. "Experimental study on lifted flames operated with liquid kerosene at elevated pressure and stabilized by outer recirculation". Flow, turbulence and combustion, 90(3), pp. 605-619.

[18] Sedlmaier, J., 2019. "Numerische und experimentelle Untersuchung einer abgehobenen Flamme unter Druck". PhD Thesis, Karlsruher Instituts für Technologie (KIT).

[19] Karami, S., Hawkes, E. R., Talei, M., and Chen, J. H., 2016. "Edge flame structure in a turbulent lifted flame: a direct numerical simulation study". Combustion and Flame, 169, pp. 110-128.

[20] Tagliante, F., Poinsot, T., Pickett, L. M., Pepiot, P., Malbec, L.-M., Bruneaux, G., and Angelberger, C., 2019. "A conceptual model of the flame stabilization mechanisms for a lifted diesel-type flame based on direct numerical simulation and experiments". Combustion and Flame, 201, pp. 65-77.

[21] Gicquel, L. Y., Staffelbach, G., and Poinsot, T., 2012. "Large eddy simulations of gaseous flames in gas turbine combustion chambers". Progress in energy and combustion science, 38(6), pp. 782-817.

[22] Navarro-Martinez, S., and Kronenburg, A., 2011. "Flame stabilization mechanisms in lifted flames". Flow Turbulence Combust, 87, pp. 377-406.

[23] Giusti, A., Kotzagianni, M., and Mastorakos, E., 2016. "LES/CMC Simulations of Swirl-Stabilised Ethanol Spray Flames Approaching Blow-Off". Flow, Turbulence and Combustion, 97(4), pp. 1165-1184.

[24] , 2009. Applicability of a Flamelet and a Presumed JPDF 2Domain-1-Step-Kinetic Turbulent Reaction Model for the Simulation of a Lifted Swirl Flame, Vol. Volume 2: Combustion, Fuels and Emissions of Turbo Expo: Power for Land, Sea, and Air.

[25] Van Oijen, J. A., Donini, A., Bastiaans, R. J. M., ten Thije Boonkkamp, J., and de Goey, L., 2016. "State-of-theart in premixed combustion modeling using flamelet generated manifolds". Progress in Energy and Combustion Science, 57, pp. 30-74.

[26] Tay-Wo-Chong, L., Zellhuber, M., Komarek, T., Im, H. G., and Polifke, W., 2016. "Combined Influence of Strain and Heat Loss on Turbulent Premixed Flame Stabilization". Flow, Turbulence and Combustion, pp. 263-294.

[27] Klarmann, N., Sattelmayer, T., Geng, W., and Magni, F.,
2016. "Flamelet Generated Manifolds for Partially Premixed, Highly Stretched and Non-Adiabatic Combustion in Gas Turbines". 54th AIAA Aerospace Sciences Meeting(January), pp. 1-14.

[28] Syred, N., 2006. "A review of oscillation mechanisms and the role of the precessing vortex core (pvc) in swirl combustion systems". Progress in Energy and Combustion Science, 32(2), pp. 93-161.

[29] ANSYS, 2019. Fluent 19 Theory Guide.

[30] Lilly, D. K., 1992. "A Proposed Modification of the Germano-Subgrid-Scale Closure Method". Physics of Fluids A, 4(3), pp. 633-635.

[31] Poinsot, T., and Veynante, D., 2005. Theoretical and $\mathrm{Nu}$ merical Combustion.

[32] Goodwin, D. G., Speth, R. L., Moffat, H. K., and . Weber, B. W., 2018. Cantera: An object-oriented software toolkit for chemical kinetics, thermodynamics, and transport processes.

[33] Tay-Wo-Chong, L., Scarpato, A., and Polifke, W., 2017. "LES Combustion Model with Stretch and Heat Loss Effects for Prediction of Premix Flame Characteristics and Dynamics". In Proceedings of ASME Turbo Expo 2017: Turbomachinery Technical Conference and Exposition, pp. 1-12.

[34] Nassini, P. C., Pampaloni, D., Andreini, A., and Meloni, R., 2019. "Large Eddy Simulation of Lean Blow-off in a Premixed Flame". In Proceedings of ASME Turbo Expo 2019, no. GT2019-90856.

[35] Nassini, P. C., Pampaloni, D., and Andreini, A., 2019. "Inclusion of Flame Stretch and Heat Loss in LES Combustion Model". In AIP Conference Proceedings, Vol. 2191.

[36] Meneveau, C., and Poinsot, T., 1991. "Stretching and quenching of flamelets in premixed turbulent combustion". Combustion and Flame, 86(4), pp. 311-332.

[37] Nassini, P. C., Pampaloni, D., and Andreini, A., 2018. "Impact of Stretch and Heat Loss on Flame Stabilization in a Lean Premixed Flame approaching Blow-off'. In Energy Procedia, Vol. 148C, pp. 250-257.

[38] Cessou, A., Maurey, C., and Stepowski, D., 2004. "Parametric and statistical investigation of the behavior of a lifted flame over a turbulent free-jet structure". Combustion and flame, 137(4), pp. 458-477. 